\title{
Reinterpreting the Frisch parameter in the field of personal taxation: a link between taxable capacity and social marginal utility in Optimal Taxation
}

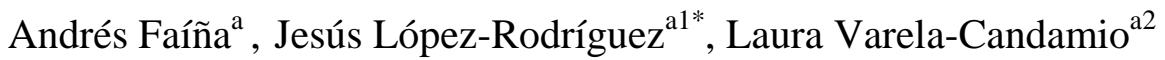 \\ ${ }^{a}$ Facultad de Economía y Empresa y Grupo Jean Monnet de Competencia y Desarrollo, \\ Campus de Elviña, s|n, A Coruña (Spain), \\ \{ $\underline{\text { fai }}$; jelopez; laura.varela.candamio\}@udc.es
}

\begin{abstract}
We give an objective meaning to the concept of taxable capacity and also establish a theoretical link between OTT and the proposals of Carter and Meade Reports, solving at the same time Kay's (2008) criticism to both approaches.
\end{abstract}

Keywords: Frisch parameter; taxable capacity; social marginal utility; Optimal taxation; Carter Report; Meade Report

JEL Classification: D63; H21; H24; H30

\footnotetext{
${ }^{1}$ Harvard University, Department of Economics, Littauer Center, 1805 Cambridge Street, Cambridge, MA 02138 .

${ }^{2}$ Suffolk University, Department of Economics, 73 Tremont Street, 10 ${ }^{\text {th }}$ floor, Boston, MA, 02108

*Corresponding author: Laura Varela-Candamio P. $34981167000 ;$ F. 34981167070

**OTT: Optimal Taxation Theory; FP:Frisch parameter; $\mathrm{NC}(\mathrm{Y})$ : necessary consumption; $\mathrm{DY}(\mathrm{Y})$ : discretionary income
} 


\section{Introduction}

Measuring tax capacity has always been a challenge in personal taxation. The proposals arising from Carter (1975) and Meade (1978) reports spin around this concept which has its limitations in terms of definition and empirical implementation (see Meade Report, 1978, p.14). Based on the aforementioned problems, over the last decades OTT (Mirrlees, 1971) and the so-called Dynamic OTT (Acemoglu et al, 2010, Golosov et al. 2011), based on the use of utilitarian social welfare functions, have become the predominant strands in the literature of taxation. However, these theories are also lacking a fully objective nature. According to Kay (2008, p.660): 'if one is to maximize a social welfare function based on an aggregation of individual circumstances, it is necessary to envisage some agreement on what the individual arguments of that social welfare function (call them utilities) would be. (...) I believe it is difficult to argue that it is possible to define utilities but not to define taxable capacities'.

Using IAS (Indirect Addilog System), we demonstrate that the FP provides a valuable contribution to the field of personal taxation, which to a large extent overcomes its pure cardinality connotation of marginal utility of income. In IAS the strict concept of a minimum consumption of subsistence presented in traditional consumption models can be substituted for a more flexible concept of necessary consumption that can be better routed in the values and consumption priorities of households according to their living standards. Moreover, it can be estimated empirically from expenditure shares in households' budget surveys drawing on the new developments in the theory of computable general equilibrium.

\section{IAS and priority needs}

Let us consider an IAS model, consumption or budget shares are given by the following expression (see Somermeyer and Langhout, 1972) ${ }^{3}$ :

$$
w_{i}=\frac{c_{i}\left(Y / p_{i}\right)^{\alpha_{i}}}{\sum_{k=1}^{n} c_{k}\left(Y / p_{k}\right)^{\alpha_{k}}}
$$

\footnotetext{
${ }^{3}$ The IAS model was independently proposed by Leser (1941) and Somermeyer and Wit (1972), in order to improve the explanatory capabilities of the main tools developed so far.
} 
where $\mathrm{w}_{\mathrm{i}}$ represents the budget shares on commodity $i, \mathrm{p}_{\mathrm{k}}$ is the price on commodity $\mathrm{i}$, $\mathrm{Y}$ is the total expenditure.

The coefficients, $\mathrm{c}_{\mathrm{k}}$ are called "preference coefficients" and $\alpha_{k}$, reaction parameters, which capture relative urgency of consumption needs. The lower the value of $\alpha_{k}$, the more urgent the consumption of $\mathrm{k}$ may be considered to be. Therefore, $\alpha_{k}$ modulates how "real income" or "purchase power" $\left(Y / p_{i}\right)$ is allocated to most priority needs or discretionary items. In order to have a well behaved indirect utility function (De Boer et al. 2010) they must fulfill the conditions: $\mathrm{c}_{\mathrm{i}} \geq 0$ and $\alpha_{i} \geq-1$ for all $\mathrm{i}=1, \ldots, \mathrm{n}$, being $\sum_{i=1}^{n} c_{i}=1$

The indirect utility function (V) associated with budget shares' (expression (1) (Heij et al., 2004) is given by ${ }^{4}$ :

$$
V(p, Y)=\sum_{i=1}^{n} c_{i}\left[\frac{\left(Y / p_{i}\right)^{\alpha_{i}}-1}{\alpha_{i}}\right]
$$

Income elasticities can be easily obtained from expenditure shares $\left(w_{i}=x_{i} p_{i} / Y\right)$ :

$$
\begin{gathered}
E\left(x_{i}, Y\right)=\frac{\partial x_{i}}{\partial Y} \frac{Y}{x_{i}}=1+\alpha_{i}-\bar{\alpha} \\
\text { where } \bar{\alpha}=\sum_{j} w_{j} \alpha_{j}
\end{gathered}
$$

Expression (3) classifies commodity $\mathrm{i}$ as necessary ${ }^{5}$ when $\mathrm{i} \in \mathrm{I}_{\mathrm{N}} \leftrightarrow \alpha_{i}<\bar{\alpha}$ and as discretionary when $\mathrm{j} \in \mathrm{I}_{\mathrm{D}} \leftrightarrow \alpha_{i}>\bar{\alpha}$, i.e., if their income elasticity is greater or less than unity, respectively.

\section{The Frisch parameter as a measure of taxable capacity}

\footnotetext{
${ }^{4}$ Commodities' demands are derived from the indirect utility function by applying Roy's identity: $x_{i}=\partial V(p, m) / \partial p_{i} / \partial V(p, m) / \partial m$.

${ }^{5} \operatorname{In} N C(Y)$ the average shares of expenditure, wi, are greater than their marginal shares.
} 
The fundamental idea underlying the concept of taxable capacity as discretionary income is the one referring to human needs priorities. In IAS, we are able to define necessary consumption $(\mathrm{NC}(\mathrm{Y}))$ and discretionary income $(\mathrm{DY}(\mathrm{Y})$ ) according to the own taxpayers' consumption priorities along different income levels.

$$
\begin{aligned}
& N C(Y)=\sum_{i \in I_{N}} x_{i} p_{i} \quad \text { where } \alpha_{i}<\bar{\alpha} \\
& D Y(Y)=\sum_{j \in I_{D}} x_{j} p_{j} \quad \text { where } \alpha_{j}<\bar{\alpha}
\end{aligned}
$$

The concept of discretionary income is simply the counterpart of non-priority income, (DY=Y-NC). The marginal utility of income or Lagrange multiplier of consumers' optimizations, $\lambda$, can be easily obtained from the expression (2), ranging between $(\infty, 0)$

$$
\lambda=\frac{\partial V(p, Y)}{\partial Y}=\sum_{i=1}^{n} c_{i} p_{i}^{-\alpha_{i}} Y^{\alpha_{i}-1}
$$

These expressions have a very important insightful meaning. When the households' income is low all consumption is devoted to the goods of higher priority and therefore the satisfaction that involves the purchase of the first unit of the good, $\lambda$, is infinite. As household income increases, the consumption of these goods increase until successive units of these goods do not result in increases of welfare. Then, consumption would lead to the next nearest priority good in the scale of preferences according to the standard livings of the society.

Therefore, FP, the elasticity of the marginal utility of income, $\varphi$, can be obtained as follows:

$$
\varphi=\frac{Y}{\lambda} \cdot \frac{\partial \lambda}{\partial Y}=\sum_{k=1}^{n} w_{k}\left(a_{k}-1\right)=\sum_{k=1}^{n} w_{k} a_{k}-\sum_{k=1}^{n} w_{k}=(\bar{\alpha}-1)
$$


where $\bar{\alpha}=\sum_{k} w_{k} \alpha_{k}$ is the weighted sum of reactions parameters and may be decomposed into two parts corresponding to the necessary consumption, $\bar{\alpha}_{N}$, and discretionary consumption, $\bar{\alpha}_{D}$, as follows:

$$
\begin{aligned}
& \bar{\alpha}_{N}=\sum_{i \in I_{N} N} w_{i} \cdot \alpha_{i} \\
& \bar{\alpha}_{D}=\sum_{j \in I_{D}} w_{j} \cdot \alpha_{j}
\end{aligned}
$$

Therefore, according to equations 8, 9 and 10, FP can be redefined:

$$
\varphi=\left[\bar{\alpha}_{N}+\bar{\alpha}_{D}-1\right]
$$

The FP measures willingness of consumers to substitute between consumption of high priority (necessaries) and non-priority (discretionary) goods. Its absolute value ranges between $\bar{\alpha}_{N}-1$ and $\bar{\alpha}_{D}-1$, respectively, at the bottom and top of income distribution. If income levels rise continuously, purchases tend to expand to the non-necessary goods and consequently, $\bar{\alpha}_{N}$ decreases and $\bar{\alpha}_{D}$ increases. Therefore, FP ranges between -2 and $0^{6}$ (Figure 1).

The pattern of behavior of the FP, decreasing in absolute value as income rises, describes the degree of urgency of basic human needs along income levels. When the ability to pay taxes is related to the discretionary income, (equation 10), the FP is reinterpreted as an indicator of taxable capacity. Since FP can be empirically estimated, new exciting research lines are open to formulate social assessment criteria of taxable capacity backed up in terms of consumers' values and expenditure priorities.

\footnotetext{
${ }^{6}$ At the lower level of income, purchases are concentrated in a single good with $\alpha_{i}=-1$. Therefore, $\varphi=\left[\bar{\alpha}_{N}+\bar{\alpha}_{D}-1\right]=\sum_{j} w_{N} \alpha_{N}+\sum_{j} w_{D} \alpha_{D}-1=1 *(-1)+0-1=-2$. Bear in mind that the behavior of FP is based on a theoretical point of view so we considered $\alpha_{i}=1$ as the maximum value for a logical economic interpretation of these parameters.
} 
Figure1. Marginal utility of income and Frisch parameter

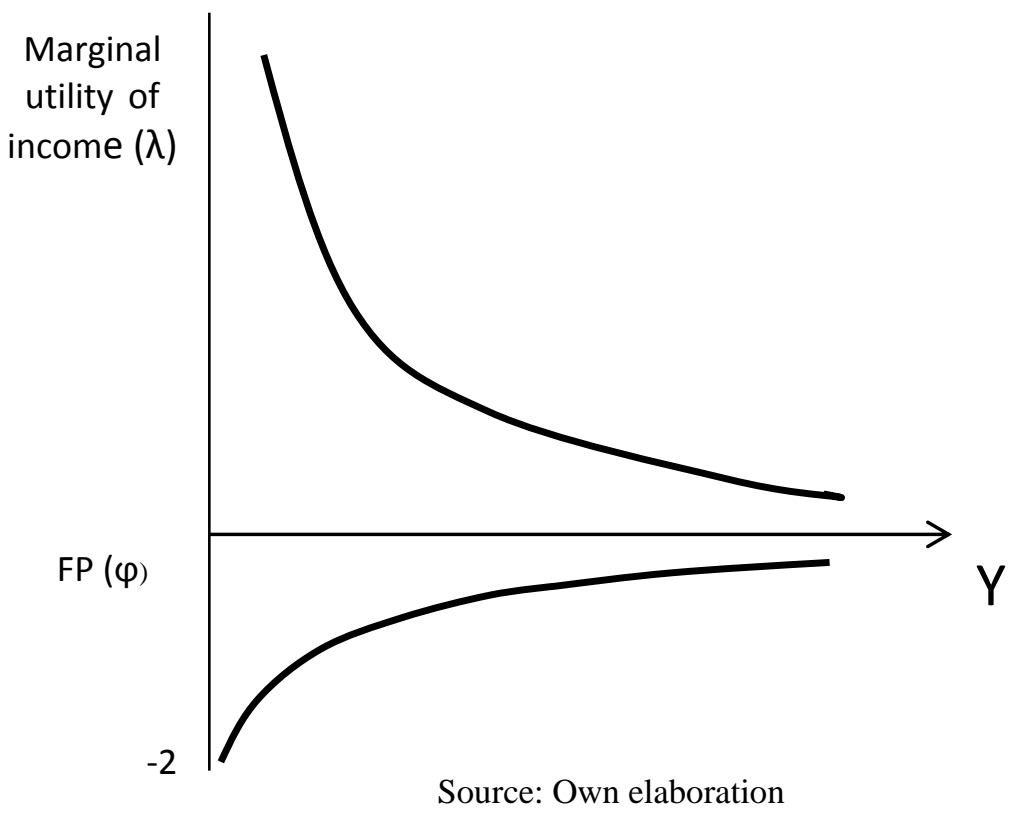

\section{The Frisch parameter as a measure of social marginal utility in OTT}

In the field of OTT, when using symmetric and additive separable social welfare functions à la Atkinson (1970), the parameter representing the social marginal utility of income for taxpayer $h, \beta^{h}$, becomes the individual marginal utility of income, $\lambda$, which can be estimated from consumers' expenditure surveys by means of IAS (as we have seen in the previous section). Therefore, on the one hand, the FP can be associated with the assessment of social welfare in the OTT and, on the other hand, a bridge can be established between the definition of taxable capacities which lie at the heart of the Meade Report (1978) and the concept of social marginal utility of income in the OTT.

Departing from the very well-known result in Diamond and Mirrlees (1971, p. 270), at the optimum, changes in the social marginal utility (or welfare) are proportional to the total tax revenue after paying taxes. This variation has two components: a) evaluating the utility of such taxpayer, $u^{h}$, under a social welfare function, $\mathrm{W}$, and $\mathrm{b}$ ) the valuation of the loss of income of the taxpayer, $h$, according to the marginal utility of income level that corresponds to your living standard and income, $\lambda^{h}$ : 


$$
\beta^{h}=\frac{\partial W}{\partial u^{h}} \lambda^{h}
$$

Considering social welfare functions, W, à la Atkinson, condition a) is equal to 1 (taxpayers' behavior would be the same) and, therefore, the weighted social marginal utility matches with the marginal utility of income of consumer $h, \lambda^{h}$.

$$
\beta^{h}=\lambda^{h}
$$

The $\beta^{h}$ parameter can be identified with the marginal utility of income (Lagrange multiplier $\lambda$ studied previously under IAS) of consumer $h$ according to his living standards. The FP can be reinterpreted in the OTT as the elasticity of social marginal utility of income. In this way, a new line to link the social marginal value of income with the degree of relative urgency in the satisfaction of the basic human needs is open.

\section{Conclusions}

In this paper a non-existent meaning to the concept of taxable capacity is given in the field of personal taxation by means of Frisch parameter. Using an Indirect Addilog System, we give it an objective nature which can be interpreted in terms of utility; redefining and conciliating the approaches of taxable capacity and Optimal Taxation Theory.

Therefore, on the one hand, the role of the government in designing tax methods would be simplified in a great deal and, on the other, tax burden could be defined according to the households' consumption priority needs. Once again, discretionary income reinterpreted by means of the FP becomes a key element to measure households' welfare and their taxable capacities (Carter Report, 1975). An important advantage of our results and their potential empirical implementation (using Households Budget Surveys) is that a precise meaning in terms of taxpayers' utility or welfare can be given to the concept of taxable capacity defined in the Carter Report (1975). Finally, another important outcome is that we are able to offer a way out to Kay's (2008) criticism to the subjective nature of the concepts of taxable capacity (Carter Report, 1975) and to utility or welfare (OTT) which would back up in the own taxpayers' consumption patterns and expenditure priorities. A very promising research line based on these theoretical results 
would be to estimate the FP using micro-data from the so-called Households Budget Surveys and explore its implications in the field of personal taxation.

\section{Acknowledgements}

\section{References}

Acemoglu, D., Golosov, M. and Tsyvinski, A. (2010) "Dynamic Mirrlees Taxation under Political Economy Constraints", The Review of Economic Studies, 77(3), 841881.

Atkinson, A.B., 1970. On the measurement of inequality. Journal of economic theory, 2, 244263.

Carter Report, 1975. Informe de la Real Comisión de Investigación sobre la Fiscalidad (Canadá)". Instituto de Estudios Fiscales. Madrid.

De Boer, P.M.C. (2010). Modeling household behavior in a CGE model: linear expenditure system or indirect addilog? Paper provided by DEGIT, Dynamics, Economic Growth, and International Trade in its series DEGIT Conference Papers with number c015_059, available at: http://www.degit.ifw-kiel.de/papers/degit_15/c015_059.pdf

Diamond, P. A., Mirrlees, J. A,, 1971. Optimal Taxation and Public Production II: Tax Rules. American Economic Review, 61(3), 261-278.

Golosov, M., Troshkin, M. and Tsyvinski, A. (2011) Optimal Taxation: Merging Micro and Macro Approaches", Journal of Money Credit and Banking, 43, 147-174.

Heij, C., P.M.C. de Boer, P.H. Franses, T. Kloek and H.K. van Dijk (2004) Econometric Methods with Applications to Business and Economics, Oxford University Press, Oxford, UK.

Kay, J., 2010. Commentary on J. Banks and P. Diamond 'The Base for Direct Taxation', in J. Mirrlees et al (eds). Dimensions of Tax Design: TheMirrlees Review. Oxford: Oxford University Press for Institute for Fiscal Studies, 656-663.

Leser, C.E:V. (1941). Family budget data and price elasticity of demand. Review of Economic Studies, 9, 40-57.

Meade, J., 1978. The structure and Reform of Direct Taxation: Report of a Committee chaired by Professor J.E. Meade for the Institute for Fiscal Studies, London: George Allen\&Unwin. http://www.ifs.org.uk/publications/3433.

Mirrlees, J.A., 1971. An exploration in the Theory of Optimum Income Taxation. The Review of Economic Studies, 38 (2), 175-208

Somermeyer, W.H and A. Langhout (1972). Shapes of Engel curves and demand curves: implications of the expenditure model, applied to Dutch data, European Economic Review, 3, 351-86. 